\title{
E-cadherin genetic variants predict survival outcome in breast cancer patients
}

\author{
Hager Memni ${ }^{1,2}$, Yosra Macherki ${ }^{1,3}$, Zahra Klayech ${ }^{1,3}$, Ahlem Ben-Haj-Ayed ${ }^{1,2}$, Karim Farhat ${ }^{4}$, Yassmine Remadi ${ }^{1}$, \\ Sallouha Gabbouj ${ }^{1}$, Wijden Mahfoudh ${ }^{1}$, Nadia Bouzid ${ }^{1,5}$, Noureddine Bouaouina ${ }^{1,5}$, Lotfi Chouchane ${ }^{6}$, \\ Abdelfattah Zakhama ${ }^{1,7}$ and Elham Hassen ${ }^{1,3^{*}}$
}

\begin{abstract}
Background: E-cadherin is a major component of adherens junctions that regulates cell shape and maintains tissue integrity. A complete loss or any decrease in cell surface expression of E-cadherin will interfere with the cell-to-cell junctions' strength and leads to cell detachment and escape from the primary tumor site. In this prospective study, three functional single nucleotide polymorphisms (-347G/GA, rs5030625; -160C/A, rs16260; +54C/T, rs1801026), were found to modulate E-cadherin expression.
\end{abstract}

Methods: 577 DNA samples from breast cancer (BC) cases were genotyped by polymerase chain reaction-restriction fragment length polymorphism (PCR-RFLP).

Results: We detected no significant correlations between each polymorphism and the clinical parameters of the patients whereas the GACC haplotype was significantly associated with low SBR grading. Overall survival analysis showed that both $-347 \mathrm{G} / \mathrm{G}$ and $+54 \mathrm{C} / \mathrm{C}$ wild (wt) genotypes had a significantly worse effect compared to the other genotypes (non-wt). Moreover, carrying simultaneously both the -347 and +54 wt genotypes confers a significantly higher risk of death. However, with metastatic recurrence, the death-rate was null in patients carrying the non-wt genotypes, and attained 37\% in those carrying the wt genotype. A multivariate analysis showed that these two polymorphisms are independent prognostic factors for overall survival in $B C$ patients.

Conclusions: Our results support the fact that E-cadherin genetic variants control disease severity and progression and could be a marker of disease outcome. These findings could be useful in selecting patients that should be monitored differently.

Keywords: E-cadherin, SNP, Prognosis, Breast cancer

\section{Background}

In 2012, one out of four cancer cases is a breast cancer (BC) case [1]. In North African countries BC is also the commonest cancer among women, and the incidence rates are widely lower than in European Mediterranean countries [2]. The incidence is probably underestimated in these developing countries because of the difficulties related to screening and diagnostic programs. However, considering death rates, $\mathrm{BC}$ is the second cause of

\footnotetext{
*Correspondence: elham.hassen@isbm.rnu.tn

${ }^{1}$ Laboratory of Molecular Immuno-Oncology, Faculty of Medicine

of Monastir, Monastir University, 5019 Monastir, Tunisia

Full list of author information is available at the end of the article
}

cancer death in more developed regions (198,000 deaths) and remains the most frequent in less developed regions (324,000 deaths). Yet, whatever socioeconomic status, it is well known that $\mathrm{BC}$ is a multifactorial disease, and that besides environment and lifestyle, the genetic background contributes to the increase of the risk of having breast cancer. While a huge amount of studies reported the involvement of genes, genetic loci or genetic polymorphisms in breast cancer susceptibility, studies of the genetic influence on disease progression and severity are less frequent [3]. Defining in gene-candidates, single nucleotide polymorphisms (SNPs) associated with increased severity or worsening progression of $\mathrm{BC}$ will potentially allow a better individualized handling 
of patients and as well as a better understanding of the mechanisms of cancer progression [4-6].

$\mathrm{BC}$ recurrence or metastasis represents the main cause of breast cancer-related deaths. It has been shown that epithelial-mesenchymal transition (EMT), a process by which epithelial cells acquire mesenchymal stem cell proprieties, plays a critical role in promoting metastasis in carcinomas [7]. One of the initiating steps of EMT involves downregulation and relocation of the main epithelial cell adhesion protein, the epithelial-cadherin (E-cadherin) [8]. In normal epithelial tissues, E-cadherin is a major component of adherens junctions that regulates cell shape and maintains tissue integrity [9]. A complete loss of E-cadherin expression/function or any decrease in cell surface expression, caused by mutation of the $C D H 1$ gene, or other mechanisms that decrease E-cadherin expression will interfere with the cell-to-cell junctions' strength and leads, inter alia, to cell detachment and escape from the primary tumor site. The CDH1 gene (OMIM 192090) is located on chromosome 16q22, several single nucleotide polymorphisms (SNP) localized in non-coding sequences and affecting protein expression were described. The $-347 G / G A$ (rs5030625) and $-160 C / A$ (rs16260) SNPs within the promoter region are the most extensively studied CDH1-SNPs in disease association studies. Both the minor alleles were previously shown to reduce E-cadherin expression by affecting the transcriptional efficiency of the $\mathrm{CDH} 1$ gene. The $-347 G A$ allele has weak transcriptional factor-binding strength and transcriptional activity compared with that of the $\mathrm{G}$ allele [10], while the $-160 \mathrm{~A}$ allele decreases the transcriptional efficiency compared with that of the $\mathrm{C}$ allele [11]. Additional regulatory polymorphisms outside of the promoter region that influence E-cadherin expression have also been reported. The $+54 C / T$ ( $r s 1801026)$ is located at $141 \mathrm{bp}$ upstream of the poly-A signal in the $3^{\prime}$-UTR region. The study of Jacobs et al. showed that the occurrence of the $\mathrm{T}$ allele is related to a lower mRNA stability and also a reduced luciferase expression by a reporter gene constructs driven by a constitutive SV40promoter [12]. In regards to breast cancer, few investigations have been carried out on the association between CDH1 polymorphisms and cancer severity or progression. This is why in this prospective cohort study conducted on 577 sporadic BC cases, three functional SNPs from of the E-cadherin gene $(C D H 1)$ were genotyped, and the possible prognostic values of these genetic variations were investigated.

\section{Methods}

\section{Study population}

The study was approved by the National Ethical Committee and a written informed consent was obtained from all enrolled individuals prior to their participation. Both patients and controls were collected between 2000 and 2012 from the Farhat Hached University Hospital of Sousse (Tunisia). During blood sampling, all participants (patients and controls) were interviewed using a questionnaire to collect demographic characteristics, personal and family medical history, contraceptive methods, sexual and reproductive behavior information and lifestyle (smoking, alcohol consumption). In this study, unrelated participants without family history of breast cancer or any cancer were included. A total of 577 breast cancer patients were recruited from the Department of Cancerology and Radiotherapy (Farhat Hached University Hospital, Sousse, Tunisia). A detailed description of the clinico-pathological characteristics of this cohort is presented in Table 1 . The patients had a mean age of $48.7 \pm 11$ years (range 23-81). The median follow-up was 70 months (range 1-144 months). At the time of this study, 145 patients relapsed after treatment (local or distant recurrence). Among them, 31 patients died from breast carcinoma. To estimate linkage disequilibrium (LD), 300 Tunisian healthy blood donors without a personal history of cancer were recruited as control group from the Regional Center of Blood Transfusion (Farhat Hached University Hospital, Sousse, Tunisia).

\section{Genomic DNA extraction and SNP genotyping analysis}

Genomic DNA was extracted from peripheral blood leukocytes by a "salting out" procedure [13]. Briefly, $10 \mathrm{ml}$ of blood was mixed with Triton lysis buffer $(0.32 \mathrm{M}$ sucrose, $1 \%$ Triton X-100, $5 \mathrm{mM} \mathrm{MgCl}, 10 \mathrm{mM}$ Tris- $\mathrm{HCl}, \mathrm{pH}$ 7.5). The pellet was incubated with proteinase $\mathrm{K}$ at $56^{\circ} \mathrm{C}$ and subsequently salted out using a saturated $\mathrm{NaCl}$ solution. Precipitated proteins were removed by centrifugation. The DNA in supernatant fluid was precipitated with ethanol. Finally, the DNA pellet was conserved in TrisEDTA buffer. DNA concentration and quality were analyzed by thermo-scientific NanoDrop $2000^{\mathrm{TM}}$.

Genotype analysis of the $C D H 1$ gene SNP $-347 \mathrm{G} /$ $G A$ (rs5030625), $-160 C / A$ (rs16260) and $+54 C / T$ (rs1801026) polymorphisms were performed by polymerase chain reaction-restriction fragment length polymorphism (PCR-RFLP) using previously described primers (Table 2) [14, 15]. Each PCR was performed under the standard conditions and the amplification was carried out in a final volume of $30 \mu \mathrm{l}$ containing $25-100 \mathrm{ng}$ of genomic DNA samples, $0.6 \mu \mathrm{M}$ of each primer for the $-160 \mathrm{C} / \mathrm{A}$ and $-347 \mathrm{G} / \mathrm{GA}$ SNPs and $0.3 \mu \mathrm{M}$ of each primer for the $+54 \mathrm{C} / \mathrm{T}$ SNP, $0.2 \mathrm{mM}$ desoxy-nucleotide tryphosphate (dNTP), $1.5 \mathrm{mM} \mathrm{MgCl}, 3 \mu \mathrm{l}$ of $10 \mathrm{X} \mathrm{PCR}$ buffer and $0.5 \mathrm{U}$ of SuperTaq DNA polymerase (Amersham, Paris, France). Reaction conditions used with thermal cycler (Biometra, Göttinger, Germany)were as 
Table 1 Clinical characteristics of breast cancer patients

\begin{tabular}{|c|c|}
\hline Characteristics & Patients (\%) \\
\hline Total & 577 \\
\hline \multicolumn{2}{|l|}{ Age at diagnosis } \\
\hline$\leq 40$ & $133(23.1)$ \\
\hline$>40$ & $444(76.9)$ \\
\hline \multicolumn{2}{|l|}{ Menopausal status } \\
\hline Non menopausal & $298(51.6)$ \\
\hline Menopausal & $279(48.4)$ \\
\hline \multicolumn{2}{|l|}{ Tumor size } \\
\hline $\mathrm{T} 1-\mathrm{T} 2$ & $381(66)$ \\
\hline T3-T4 & $167(29)$ \\
\hline Unknown & $29(5)$ \\
\hline \multicolumn{2}{|c|}{ Lymph node involvement } \\
\hline Negative & $230(39.9)$ \\
\hline Positive & $328(56.8)$ \\
\hline Unknown & $19(3.3)$ \\
\hline \multicolumn{2}{|l|}{ Metastasis } \\
\hline Negative & $362(62.7)$ \\
\hline Positive & $10(1.7)$ \\
\hline Unknown & $205(35.5)$ \\
\hline \multicolumn{2}{|l|}{ SBR grade } \\
\hline SBR 1-2 & $329(57)$ \\
\hline SBR 3 & $192(33.3)$ \\
\hline Unknown & $56(9.7)$ \\
\hline \multicolumn{2}{|l|}{ Histology } \\
\hline Ductual & $513(88.9)$ \\
\hline Lobular & $23(4)$ \\
\hline Other & $25(4.3)$ \\
\hline Unknown & $16(2.8)$ \\
\hline \multicolumn{2}{|l|}{ Estrogen receptor } \\
\hline Negative & $195(33.8)$ \\
\hline Positive & $255(44.2)$ \\
\hline Unknown & $127(22)$ \\
\hline \multicolumn{2}{|c|}{ Progesteron receptor } \\
\hline Negative & $240(41.6)$ \\
\hline Positive & $210(36.4)$ \\
\hline Unknown & $127(22)$ \\
\hline \multicolumn{2}{|l|}{ Her-2 status } \\
\hline Negative & $75(13)$ \\
\hline Positive & $39(6.8)$ \\
\hline Unknown & $463(80.2)$ \\
\hline
\end{tabular}

follows: For the promoter SNPs $-160 C / A$ and $-347 \mathrm{G} /$ GA the DNA was initially denatured for 5 min at $94{ }^{\circ} \mathrm{C}$ for 1 cycle, and incubated for 30 cycles: denaturing for $30 \mathrm{~s}$ at $94{ }^{\circ} \mathrm{C}$, annealing for $30 \mathrm{~s}$ at $61{ }^{\circ} \mathrm{C}$ and extending for $60 \mathrm{~s}$ at $72{ }^{\circ} \mathrm{C}$. The $+54 \mathrm{C} / \mathrm{T}$ PCR reaction was carried out in the same conditions described previously except for the annealing temperature, that was at $58{ }^{\circ} \mathrm{C}$.
A final extension of $7 \mathrm{~min}$ at $72{ }^{\circ} \mathrm{C}$ was performed at the end of each reaction. After amplification, PCR products were digested at $37{ }^{\circ} \mathrm{C}$ over night with $5 \mathrm{U}$ of the restriction enzyme $H p h I$ for the $-160 C / A$ SNP, for $3 \mathrm{~h}$ with $3 \mathrm{U}$ of the restriction enzyme BanII for the $-347 G / G A$ and over night with $2 \mathrm{U}$ of the restriction enzyme PmlI for the $+54 C / T$ SNP. Digestion products were, then, separated on a 3\% agarose gel stained with ethidium bromide and visualized with ultraviolet light.

\section{Statistical analysis}

To evaluate if our study population (patients and controls) is in the Hardy-Weinberg equilibrium we used the Chi square test to compare between observed and expected genotype frequencies of $\mathrm{CDH1}$ gene polymorphisms. The same test was used to evaluate any significant association between the three $C D H 1$ polymorphisms and the clinicopathological characteristics of the disease. The differences were considered significant if the $p$ value did not exceed 0.05 . Odd ratios (ORs) and 95\% confidence intervals (CIs) were calculated by unconditional logistic regression. When expected values in contingency tables were under 5, Fisher's exact test was used. The LD between SNPs pairs was quantified using the standardized linkage disequilibrium coefficient (D') [16]. The haplotypes and their frequencies were estimated using the Phase program [17].

Disease-free survival (DFS), metastasis-free survival (MFS), and overall survival (OS) were calculated using the Kaplan-Meier method for ten years and compared with the log-rank test. DFS was defined as the date of diagnosis until first recurrence, metastasis, death due to breast cancer or the last date of follow-up. MFS was defined as the date of diagnosis until first metastasis or last date of follow-up and OS was defined as the date of diagnosis until death due to breast cancer or last date of follow-up. Variables with a p-value less than 0.1 in the univariate Cox regression model were evaluated in a multivariate Cox regression model using the enter method. Because of the low number of the cases with metastasis at diagnosis $(\mathrm{n}=10)$ we choose to exclude the metastasis parameter from the haplotypes and multivariate analysis. All statistics were carried out using Software Package for Social Sciences (SPSS) version 20.0 (SPSS, Chicago, IL, USA).

\section{Results}

CDH1 SNPs and their association with clinicopathological characteristics of breast cancer patients

All DNA samples were successfully genotyped for the three CHD1 SNPs (577 patients and 300 controls). For both patient and control groups all genotype distributions did not diverge significantly from Hardy-Weinberg 
Table 2 Primers and restriction enzymes used for polymorphism genotyping

\begin{tabular}{|c|c|c|c|}
\hline SNPs & Primer sequences & Restriction enzymes & Fragments size (bp) \\
\hline \multirow{2}{*}{$\begin{array}{l}-347 \mathrm{G} / \mathrm{GA} \\
\mathrm{rs} 5030625 \\
-160 \mathrm{C} / \mathrm{A} \\
\mathrm{rs} 16260\end{array}$} & \multirow[t]{2}{*}{$\begin{array}{l}\text { Forword: 5'-GCCCCGACTTGTCTCTCTAC-3' } \\
\text { Reverse: 5'-GGCCACAGCCAATCAGCA-3' }\end{array}$} & Banll & $\begin{array}{l}G: 263+116+68 \\
G A: 332+116\end{array}$ \\
\hline & & Hphl & $\begin{array}{l}C: 181+177+89 \\
A: 266+181\end{array}$ \\
\hline $\begin{array}{l}+54 \mathrm{C} / \mathrm{T} \\
\mathrm{rs} 1801026\end{array}$ & $\begin{array}{l}\text { Forword: 5'-CAGACAAAGACCAGGACTAT-3' } \\
\text { Reverse: 5'-AAGGGAGCTGAAAAACCACCAGCCAC-3' }\end{array}$ & $P m / l$ & $\begin{array}{l}C: 146+26 \\
T: 172\end{array}$ \\
\hline
\end{tabular}

equilibrium. Moreover, the minor allele frequencies (MAF) of these variants in the control population were close to those reported in Europeans (HapMap consortium) (-347GA: 0.150; -160A: 0.322 and +54T: 0.206). Among the patients, the $-347 G / G A$ genotype frequencies were $72.4 \%$ for $G G, 24.8 \%$ for $G G A$ and $2.8 \%$ for GAGA. For the $-160 C / A \mathrm{SNP}$, genotype frequencies were $45.9 \%$ for $C C$, $43.7 \%$ for $C A$ and $10.4 \%$ for $A A$. The $+54 C / T$ genotype frequencies were $35.6 \%$ for $C C, 47.1 \%$ for $C T$ and $17.3 \%$ for $T T$.

We then investigated the association between CHD1 SNP genotype distributions and clinicopathological characteristics at diagnosis of patients with breast cancer. For each SNP genotype analysis, the patients were divided into homozygous wild-type carriers (wt) and non-carriers (non-wt, heterozygous and homozygous mutant). The relationships between CHD1 SNP genotypes and clinicopathological characteristics are shown in Table 3. Overall, no statistically significant association was observed with any of the three SNPs and clinical characteristics, including age, menopausal status, tumor size, lymph node involvement, metastasis, SBR grading and histologic type.

To analyze the association of the combined effects of the CDH1 SNPs and clinicopathological characteristics of patients with breast cancer, $C D H 1$ haplotype frequencies and linkage disequilibrium coefficient were estimated. The haplotype frequencies among both patients and controls are summarized in Table 4. Eight different haplotypes were observed among both controls and patients with breast cancer. The $-347 G-160 C+54 C$ haplotype was the most frequent among both controls and patients. The $-347 G-160 A+54 T$ haplotype was significantly more frequently observed in patients than controls, and seemed to be a risk haplotype for $\mathrm{BC}$ occurrence ( $\mathrm{p}<10^{-4}$, OR $\left.=4.03\right)$. However, further larger population-based case-control studies are necessary to validate these findings. The LD analysis results showed different patterns between cases and controls. Both $-347 \mathrm{G} /$ $G A$ and $-160 C / A$ loci, and $-160 C / A$ and $+54 C / T$ loci showed a stronger LD in controls compared to patients $\left(D^{\prime}=0.484\right.$ versus $D^{\prime}=0.279$ and $D^{\prime}=0.473$ versus $\left.D^{\prime}=0.070\right)$. Moreover, the $-347 \mathrm{G} / \mathrm{GA}$ and $+54 \mathrm{C} / \mathrm{T}$ loci showed a higher LD in controls compared to patients $\left(D^{\prime}\right.$ $=0.083$ versus $\left.D^{\prime}=0.015\right)$. The relationships between CHD1 SNP haplotypes and clinicopathological characteristics are shown in Table 5. The most frequent haplotype was used as a reference in the correlation analysis. The results showed that the $-347 G A-160 C+54 T$ haplotype was significantly more frequent among the younger women $($ age $\leq 40)(\mathrm{p}=0.01, \mathrm{OR}=0.37)$. However, the $-347 G A-160 C+54 C$ haplotype was significantly more frequent among patients aged more than 40 years $(\mathrm{p}=0.015$, OR $=3.74)$. The $-347 \mathrm{GA}-160 \mathrm{C}+54 \mathrm{C}$ haplotype was also significantly more frequent among women with low SBR grading compared to high SBR grading $(\mathrm{p}=0.049$, OR $=0.44)$. There was no more significant correlation of $C D H 1$ haplotypes with clinical characteristics, including menopausal status, tumor size and lymph node involvement and histological type.

\section{CDH1 SNPs and clinicopathological characteristics associated with survival in patients with breast cancer}

When the relationship between the genotype distribution of the three SNPs in overall patients and the DFS and MFS was tested, no significant differences were observed (data not shown). However, the 10-years OS curve analysis and log-rank testing showed that both the $-347 G / G$ and $+54 C / C$ wild homozygous genotypes had a significantly worse effect on OS compared to the other genotypes (survival rate: 90 versus 95\% and 91 versus 99\%, respectively) (Fig. 1). Moreover, when patients carrying simultaneously both the $-347 G / G$ and $+54 C / C$ genotypes were grouped and compared to the non-carrier patients, the survival rate decreased to $87 \%$ for the wtcarriers and increased to $100 \%$ for the non-wt carriers (Fig. 1).

Further analyses were conducted to investigate whether the $-347 G / G A$ and $+54 C / T$ SNPs were associated with overall survival, according to clinical characteristics of the breast cancer patients (tumor size, lymph node involvement, SBR grading and metastasis occurrence after treatment). Significantly worse survival rates were observed in patients carrying the $-347 G / G$ wild homozygous genotype among patients with T3-T4 tumor size (survival rates: 88 versus 100\%), or positive 
Table 3 Correlation between CDH1 SNPs and clinicopathological characteristics of breast cancer patients

\begin{tabular}{|c|c|c|c|c|c|c|c|c|c|c|c|c|}
\hline \multirow[t]{2}{*}{ Characteristics } & \multicolumn{4}{|c|}{$-347 G / G A$} & \multicolumn{4}{|c|}{$-160 \mathrm{C} / \mathrm{A}$} & \multicolumn{4}{|c|}{$+54 \mathrm{C} / \mathrm{T}$} \\
\hline & $G G^{\mathbf{b}}$ & $G G A+G A G A$ & $P$ & OR $(95 \% \mathrm{Cl})$ & $C C^{\mathbf{b}}$ & $C A+A A$ & $P$ & OR $(95 \% C l)$ & $C C^{\mathbf{b}}$ & $C T+T T$ & $P$ & OR $(95 \% C l)$ \\
\hline \multicolumn{13}{|l|}{ Age at diagnosis } \\
\hline$\leq 40$ & 96 & 37 & & & 61 & 72 & & & 48 & 85 & & \\
\hline$>40$ & 322 & 122 & 0.93 & $0.98(0.63-1.51)$ & 204 & 240 & 0.98 & $0.99(0.67-1.47)$ & 157 & 287 & 0.87 & $1.03(0.68-1.54)$ \\
\hline \multicolumn{13}{|l|}{ Menopausal status } \\
\hline Non menopausal & 225 & 73 & & & 145 & 153 & & & 107 & 191 & & \\
\hline Menopausal & 193 & 86 & 0.08 & $1.37(0.95-1.98)$ & 120 & 159 & 0.17 & $1.25(0.90-1.74)$ & 98 & 181 & 0.84 & $1.03(0.73-1.45)$ \\
\hline \multicolumn{13}{|l|}{ Tumor size } \\
\hline $\mathrm{T} 1-\mathrm{T} 2$ & 279 & 102 & & & 166 & 215 & & & 134 & 247 & & \\
\hline T3-T4 & 119 & 48 & 0.63 & $1.1(0.73-1.65)$ & 81 & 86 & 0.28 & $0.82(0.56-1.18)$ & 61 & 106 & 0.76 & $0.94(0.64-1.37)$ \\
\hline \multicolumn{13}{|c|}{ Lymph node involvement } \\
\hline Negative & 167 & 63 & & & 116 & 114 & & & 73 & 157 & & \\
\hline Positive & 239 & 89 & 0.94 & $0.98(0.67-1.44)$ & 141 & 187 & 0.08 & $1.34(0.96-1.80)$ & 127 & 201 & 0.09 & $0.73(0.51-1.05)$ \\
\hline \multicolumn{13}{|l|}{ Metastasis } \\
\hline Negative & 264 & 98 & & & 166 & 196 & & & 121 & 241 & & \\
\hline Positive & 8 & 2 & $0.46^{a}$ & $0.67(0.14-3.20)$ & 3 & 7 & $0.25^{\mathrm{a}}$ & $1.97(0.50-7.70)$ & 2 & 8 & $0.37^{a}$ & $2(0.42-9.60)$ \\
\hline \multicolumn{13}{|l|}{ SBR grade } \\
\hline SBR 1-2 & 232 & 97 & & & 150 & 179 & & & 112 & 217 & & \\
\hline SBR 3 & 148 & 44 & 0.10 & $0.71(0.47-1.07)$ & 91 & 101 & 0.69 & $0.93(0.65-1.32)$ & 74 & 118 & 0.30 & $0.82(0.56-1.19)$ \\
\hline \multicolumn{13}{|l|}{ Histology } \\
\hline Ductual & 376 & 137 & & & 240 & 273 & & & 183 & 330 & & \\
\hline Lobular & 18 & 5 & 0.59 & $0.76(0.27-2.09)$ & 11 & 12 & 0.92 & $0.95(0.41-2.21)$ & 6 & 17 & 0.35 & $1.57(0.60-4.05)$ \\
\hline
\end{tabular}

Table 4 Haplotype frequencies of CDH1 SNPs observed in breast cancer patients and controls

\begin{tabular}{|c|c|c|c|c|c|}
\hline \multicolumn{3}{|l|}{ Haplotypes } & \multicolumn{2}{|c|}{ Frequencies } & \multirow[t]{2}{*}{$P$} \\
\hline$-347 G / G A$ & $-160 C / A$ & $+54 \mathrm{C} / T$ & Patients & Controls & \\
\hline G & $C$ & $C$ & 0.323 & 0.405 & \\
\hline G & $C$ & $T$ & 0.238 & 0.265 & 0.270 \\
\hline G & $A$ & $C$ & 0.177 & 0.147 & $<10^{-4}$ \\
\hline G & $A$ & $T$ & 0.109 & 0.032 & $<10^{-4}$ \\
\hline GA & $C$ & $C$ & 0.068 & 0.101 & 0.380 \\
\hline GA & $C$ & $T$ & 0.048 & 0.024 & 0.023 \\
\hline GA & $A$ & $C$ & 0.022 & 0.021 & 0.660 \\
\hline GA & $A$ & $T$ & 0.012 & 0.003 & 0.230 \\
\hline
\end{tabular}

lymph node involvement (survival rates: 88 versus 99\%), or high SBR grading (survival rates: 86 versus 100\%) or metastasis occurrence after treatment (survival rates: 71 versus 97\%) (Fig. 2). No significant relationship was found with T1-T2 tumor size, negative lymph node involvement, or low SBR grading and non-metastasis occurrence after treatment. Moreover, no significant relationship was found when the $+54 \mathrm{C} / \mathrm{T}$ SNP was analyzed according to several patient subgroups. However, when we studied the combined effect of $-347 \mathrm{G} / \mathrm{G}$ and $+54 \mathrm{C} / \mathrm{C}$ genotypes on overall survival of the positive lymph node involvement (survival rates: 83 versus 100\%), high SBR grading (survival rates: 80 versus $100 \%$ ) and metastasis occurrence after treatment subgroups (survival rates: 63 versus $100 \%$ ), as noted previously, BC patients carrying simultaneously the wt genotypes had significantly worse survival rates (Fig. 2). Although the results were not statistically significant, when the combined effect was analyzed according to T3-T4 tumor size, they indicated that patients with $-347 G / G$ and $+54 C / C$ genotypes had the worst survival rate (survival rates: 86 versus 100\%) (Fig. 2).

Univariate and multivariate analyses were used to evaluate whether the CDH1 SNPs and the clinicopathological characteristics were independent prognostic factors of breast cancer patients. The multivariate analysis showed that tumor size $(\mathrm{p}=0.001, \mathrm{HR}=1.80)$ and lymph node involvement ( $\mathrm{p}=0.007, \mathrm{HR}=1.66)$ were independently associated with the DFS (Table 6). Moreover, it showed that lymph node involvement $(\mathrm{p}=0.018, \mathrm{HR}=3.26)$, 
Table 5 Correlation between $\mathrm{CDH} 1$ haplotype frequencies and clinicopathological characteristics of breast cancer patients

\begin{tabular}{|c|c|c|c|c|c|c|c|}
\hline Characteristics & $G C C^{a}$ & $G C T$ & $G A C$ & $G A T$ & GACC & GACT & GAAC and GAAT \\
\hline \multicolumn{8}{|l|}{ Age at diagnosis } \\
\hline$\leq 40$ & 0.358 & 0.213 & 0.194 & 0.084 & 0.027 & 0.094 & 0.030 \\
\hline$>40$ & 0.312 & 0.248 & 0.173 & 0.117 & 0.081 & 0.032 & 0.036 \\
\hline$P$ & & 0.15 & 0.83 & 0.15 & 0.015 & 0.01 & 0.21 \\
\hline OR (Cl 95\%) & 1 & $1.38(0.89-2.13)$ & $1.06(0.64-1.74)$ & $1.54(0.85-2.79)$ & $3.74(1.29-10.82)$ & $0.37(0.17-0.79)$ & $1.37(0.82-2.28)$ \\
\hline \multicolumn{8}{|l|}{ Menopausal status } \\
\hline Non menopausal & 0.354 & 0.236 & 0.172 & 0.105 & 0.056 & 0.049 & 0.028 \\
\hline Menopausal & 0.291 & 0.245 & 0.182 & 0.114 & 0.081 & 0.043 & 0.044 \\
\hline$P$ & & 0.21 & 0.26 & 0.26 & 0.098 & 0.92 & 0.25 \\
\hline OR (Cl 95\%) & 1 & $1.26(0.88-1.81)$ & $1.29(0.83-2.01)$ & $1.29(0.83-2.01)$ & $1.69(0.91-3.16)$ & $1.04(0.51-2.11)$ & $1.73(0.64-4.39)$ \\
\hline \multicolumn{8}{|l|}{ Tumor size } \\
\hline $\mathrm{T} 1-\mathrm{T} 2$ & 0.318 & 0.237 & 0.192 & 0.105 & 0.057 & 0.051 & 0.038 \\
\hline T3-T4 & 0.326 & 0.242 & 0.149 & 0.124 & 0.085 & 0.038 & 0.035 \\
\hline$P$ & & 0.91 & 0.23 & 0.6 & 0.33 & 0.46 & 0.76 \\
\hline OR (Cl 95\%) & 1 & $0.98(0.65-1.46)$ & $0.73(0.44-1.21)$ & $1.13(0.71-1.81)$ & $1.41(0.71-2.79)$ & $0.74(0.33-1.66)$ & $0.86(0.32-2.27)$ \\
\hline \multicolumn{8}{|c|}{ Lymph node involvement } \\
\hline Negative & 0.320 & 0.284 & 0.162 & 0.084 & 0.053 & 0.047 & 0.050 \\
\hline Positive & 0.323 & 0.208 & 0.195 & 0.123 & 0.080 & 0.047 & 0.023 \\
\hline$P$ & & 0.19 & 0.34 & 0.24 & 0.29 & 0.91 & 0.19 \\
\hline OR (Cl 95\%) & 1 & $0.78(0.54-1.13)$ & $1.26(0.78-2.04)$ & $1.34(0.82-2.17)$ & $1.43(0.74-2.77)$ & $0.96(0.47-1.95)$ & $0.55(0.22-1.81)$ \\
\hline \multicolumn{8}{|l|}{ SBR grade } \\
\hline SBR 1-2 & 0.314 & 0.225 & 0.167 & 0.131 & 0.086 & 0.047 & 0.030 \\
\hline SBR 3 & 0.365 & 0.230 & 0.192 & 0.085 & 0.040 & 0.055 & 0.025 \\
\hline$P$ & & 0.46 & 0.96 & 0.053 & 0.049 & 0.97 & 0.84 \\
\hline OR (Cl 95\%) & 1 & $0.86(0.57-1.29)$ & $0.99(0.61-1.61)$ & $0.61(0.37-1.00)$ & $0.44(0.19-0.99)$ & $1.01(0.50-2.05)$ & $0.91(0.34-2.42)$ \\
\hline \multicolumn{8}{|l|}{ Histology } \\
\hline Ductual & 0.291 & 0.231 & 0.139 & 0.157 & 0.122 & 0.026 & 0.032 \\
\hline Lobular & 0.329 & 0.245 & 0.179 & 0.103 & 0.060 & 0.050 & 0.033 \\
\hline$P$ & & 0.74 & 0.83 & 0.2 & 0.11 & 0.52 & 0.72 \\
\hline OR (Cl 95\%) & 1.00 & $1.12(0.57-2.22)$ & $0.90(0.35-2.34)$ & $1.59(0.78-3.23)$ & $2.06(0.86-4.94)$ & $0.62(0.14-2.67)$ & $0.91(0.54-1.52)$ \\
\hline
\end{tabular}

a Reference group

$\mathrm{Cl}$ confidence interval, $O R$ odds ratio

SBR grade $(\mathrm{p}=0.048, \mathrm{HR}=2.20),-347 \mathrm{G} / \mathrm{GA} \mathrm{SNP}$ $(\mathrm{p}=0.039, \mathrm{HR}=0.12)$ and $+54 C / T$ SNP $(\mathrm{p}=0.022$, $\mathrm{HR}=0.40$ ) were independent prognostic factors for OS in breast cancer patients (Table 6).

\section{Discussion}

Previous studies have shown that the development and the progression of epithelial cancers such as $\mathrm{BC}$ are related to the loss or the reduced expression of the main intercellular adhesion molecule of epithelial cells, the E-cadherin. The loss of cell-to-cell adhesion is an early event in metastatic colonization, leading to the detachment of the cell from her tissue of origin to colonize other sites.

E-cadherin expression is under the control of functional SNPs. As far as we know, reports were mainly case control-studies looking for risk of developing $\mathrm{BC}$, and very few studies with controversial results were investigated to identify the relationship between $C D H 1$ genetic variants and clinicopathological features of the patients. In our study, none of the studied SNPs showed any significant correlations with patients' epidemiological or tumor or histological features. Shabnaz et al. also did not find any correlation between $-160 \mathrm{C} / \mathrm{A}$ polymorphisms with clinicopathological characteristics of $\mathrm{BC}$ patients [18]. However, Tipirisetti et al. noted a positive correlation between the $-160 \mathrm{~A}$ allele occurrences in patients with advanced stage [19]. In a Taiwanese study conducted on hepatocellular carcinoma patients, the occurrence of the $-160 \mathrm{~A}$ allele was significantly associated with more severe clinical stages [20]. Conversely, in a recent study of pancreatic cancer cases, the $-160 A A$ genotype was 

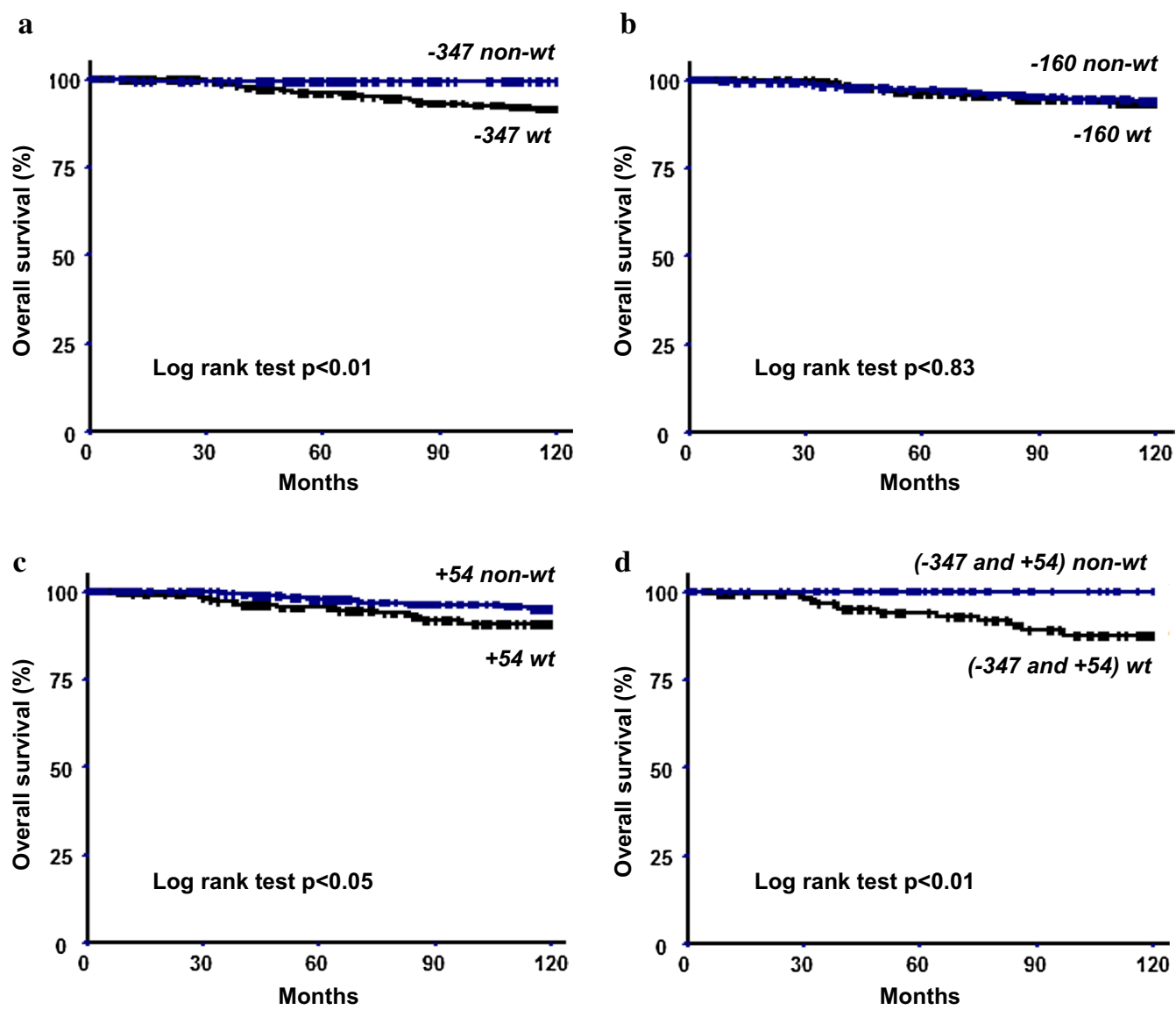

Fig. 1 Overall survival curves of breast carcinoma patients according to the presence or absence of the wild type genotypes; a $-347 G / G A$, b $-160 \mathrm{C} / \mathrm{A}, \mathbf{c}+54 \mathrm{C} / \mathrm{T}$ and $\mathbf{d}$ combined $-347 \mathrm{G} / \mathrm{GA}$ with $+54 \mathrm{C} / \mathrm{T}$

found to be significantly associated with reduced risk with $\mathrm{T}$ stage, lymph node metastasis and pathological stage [21]. In accordance with the previous results, a Japanese study of gastric cancer cases found that the $-160 C C$ genotype was significantly associated with deep invasion and lymph node metastasis [22]. Although previous studies were conducted mainly on epithelial cancer cases, a possible explanation of these contrasting results is the occurrence of one or more other SNPs, found in strong LD with the $-160 C / A$ in some ethnic groups (e.g. rs7200690, rs9929218). Further studies should be conducted among different ethnic groups to help understanding these results.

To see the combined effects of the three functional SNPs the haplotype analysis was investigated. Weak LD values, generally associated with higher recombination rates, were observed among patients [23]. Conversely, stronger LD values were observed among controls, suggesting a possible protective effect of the strong LD against BC. However, further investigations with a larger control sample size are needed to explain this result. To the best of our knowledge, this is the only study that explored the relationship between CDH1 haplotype frequencies and tumor severity. The $-347 G A-160 C+54 C$ haplotype may have a protective effect against high SBR grading. This haplotype has only one mutated allele at the -347 position, whilst having protective effect, however, the $G A$ allelic analysis did not show significant differences with the $G$ allele when patients were compared according to SBR grading $(\mathrm{p}=0.12$, OR $=0.75)$. Although each SNP had a functional impact on E-cadherin expression, the effects of their interactions and combinations are unknown, hence there is a need for further studies to describe the functionality of haplotypes including these three SNPs.

Moreover, very few studies investigated the associations of the $C D H 1$ SNPs with patient survival. In a recent study conducted on a Chinese population, Jia et al. showed that $\mathrm{BC}$ patients with low clinical tumor stages and carrying the minor allele genotype of an SNP (rs7200690) located in intron 2 in strong LD with the $-160 C / A$ SNP, had unfavorable disease-free survival [24]. 


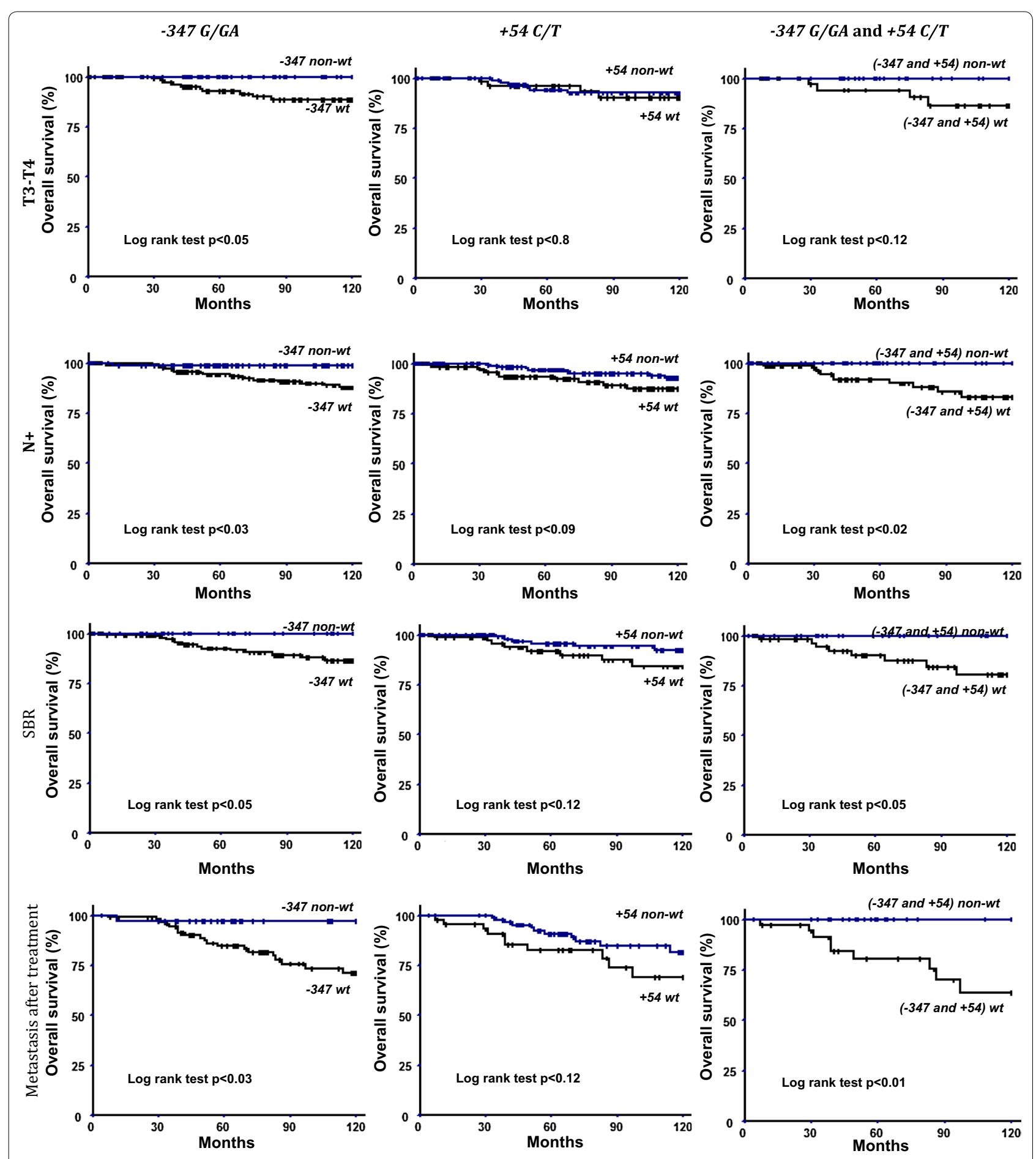

Fig. 2 Overall survival curves of different subgroups of breast carcinoma patients according to the presence or absence of the wild type genotypes of $-347 G / G A,+54 C / T$ and combined $-347 G / G A$ with $+54 C / T$

However, in a British population-based study no effect of the $-160 C / A$ SNP was seen on BC survival [25]. In the present study the $-347 G / G A$ and $+54 C / T$ SNPs, but not the $-160 C / A$ SNP, were shown to be associated with
$\mathrm{BC}$ overall survival. When considering the whole patient group, both wild genotypes were shown to be associated with worse BC overall survival. Moreover, patients carrying simultaneously the wild genotypes, $-347 G / G$ and 
Table 6 Clinicopathological characteristics associated with disease-free survival and overall survival in patients with breast cancer

\begin{tabular}{|c|c|c|c|c|c|c|c|c|c|c|c|c|}
\hline \multirow[t]{3}{*}{ Characteristics } & \multicolumn{6}{|c|}{ Disease-free survival } & \multicolumn{6}{|c|}{ Overall survival } \\
\hline & \multicolumn{3}{|c|}{ Univariate analysis } & \multicolumn{3}{|c|}{ Multivariate analysis } & \multicolumn{3}{|c|}{ Univariate analysis } & \multicolumn{3}{|c|}{ Multivariate analysis } \\
\hline & $H R$ & $95 \% \mathrm{Cl}$ & $P$ & HR & $95 \% \mathrm{Cl}$ & $P$ & HR & $95 \% \mathrm{Cl}$ & $P$ & HR & $95 \% \mathrm{Cl}$ & $P$ \\
\hline $\mathrm{Age}^{\mathrm{a}}$ & 0.74 & $0.51-1.08$ & 0.121 & ni & & & 0.75 & $0.33-1.68$ & 0.487 & ni & & \\
\hline Menopausal status ${ }^{b}$ & 0.92 & $0.66-1.28$ & 0.638 & $\mathrm{ni}$ & & & 0.87 & $0.42-1.76$ & 0.702 & ni & & \\
\hline Tumor size ${ }^{c}$ & 1.87 & $1.33-2.64$ & 0.0003 & 1.80 & $1.27-2.56$ & 0.001 & 1.44 & $0.69-3.02$ & 0.326 & ni & & \\
\hline Lymph node involvement $^{d}$ & 1.75 & $1.22-2.51$ & 0.002 & 1.66 & $1.14-2.40$ & 0.007 & 2.97 & $1.21-7.30$ & 0.017 & 3.26 & $1.22-8.69$ & 0.018 \\
\hline Metastasis $^{d}$ & 3.03 & $1.47-6.22$ & 0.003 & ni & & & 5.64 & $1.67-19.01$ & 0.005 & ni & & \\
\hline SBR grade ${ }^{e}$ & 1.09 & $0.77-1.56$ & 0.599 & ni & & & 2.29 & $1.08-4.84$ & 0.030 & 2.20 & $1.00-4.81$ & 0.048 \\
\hline Histology ${ }^{f}$ & 1.62 & $0.82-3.20$ & 0.157 & ni & & & 0.80 & $0.11-5.92$ & 0.833 & ni & & \\
\hline Estrogen receptor ${ }^{d}$ & 1.34 & $0.91-1.95$ & 0.127 & ni & & & 0.73 & $0.33-1.60$ & 0.435 & ni & & \\
\hline Progesteron receptor ${ }^{d}$ & 1.16 & $0.80-1.67$ & 0.419 & ni & & & 0.88 & $0.40-1.95$ & 0.763 & ni & & \\
\hline Her-2 status ${ }^{d}$ & 1.03 & $0.44-2.40$ & 0.938 & $\mathrm{ni}$ & & & 0.67 & $0.06-7.44$ & 0.746 & ni & & \\
\hline $\mathrm{CDH1}-347 \mathrm{G} / \mathrm{G} A^{9}$ & 0.92 & $0.63-1.35$ & 0.694 & ni & & & 0.09 & $0.01-0.68$ & 0.020 & 0.12 & $0.01-0.89$ & 0.039 \\
\hline$C D H 1-160 C / A^{9}$ & 0.92 & $0.66-1.28$ & 0.650 & ni & & & 1.27 & $0.62-2.63$ & 0.505 & ni & & \\
\hline $\mathrm{CDH1}+54 \mathrm{C} / \mathrm{T}^{\mathrm{9}}$ & 0.98 & $0.69-1.40$ & 0.951 & ni & & & 0.52 & $0.26-1.06$ & 0.075 & 0.40 & $0.18-0.87$ & 0.022 \\
\hline
\end{tabular}

$H R$ hazard ratio; $n i$ not included in multivariate analysis

a $\leq 40$ versus $>40$ years

b Non menopausal versus menopausal

c T1-T2 versus T3-T4

d Negative versus positive

e SBR 1-2 versus SBR 3

f Ductal invasive carcinoma versus Lobular invasive carcinoma

${ }^{g}$ Homozygous wild allele type versus heterozygous and mutates homozygous allele types

$+54 C / C$, had worse survival rates than those carrying one of each genotype. Interestingly, when considering more aggressive tumor subgroups (T3-T4, lymph node positive, high grade SBR and metastasis occurrence after treatment) we observed significantly worse survival rates with the $-347 G / G$ genotype and a decrease in survival when patients carry simultaneously the $-347 G / G$ and $+54 C / C$ genotypes. Herein we found that the $C D H 1$ $-347 G / G$ genotype confer risk of death in patients with more aggressive $\mathrm{BC}$ progression.

It is well known that in normal epithelial tissues, E-cadherin expression has suppressive effects on tumor progression, invasion and metastasis and thus any deregulation of E-cadherin expression could have critical pathological consequences. In a pathological context, E-cadherin expression could be modulated by several mechanisms, loss of heterozygosity, mutations of the CDH1 gene, epigenetic modulation, proteolytic processing and also cadherin switching [9]. In BC, studies on E-cadherin tissue expression were conflicting. Most of them showed that reduced or loss of E-cadherin expression correlates with high histological grade, larger tumor size, nodal metastasis, development of distant metastasis, and a reduced disease-free and overall survival
[26-28]. However, in recent reports the involvement of E-cadherin in breast cancer severity and progression has increasingly been suggested $[29,30]$. The ambiguous role of E-cadherin could be partially due to the existence of at least two different and functional forms of E-cadherin, a full-length membrane form and an extracellular proteolytic soluble form (sE-cad). During the oncogenic process the first consequence of the E-cadherin proteolysis is the cell detachment and the release of a functional sE-cad with cancer promoting functions. Inside the tumor microenvironment, sE-cad inhibits cell-tocell adhesion through an efficient competitive manner and by stimulating the activity of multiple matrix metalloproteinases (MMPs) [31]. Then, when sE-cad diffuse and spread into blood circulation, multiple oncogenic signaling pathways are activated $[32,33]$. Recently, Liang et al., assessed the clinical significance of serum sE-cad levels in BC patients. They observed a significant correlation of sE-cad levels with tumor stage, grade, lymph node metastasis and also survival [34]. Moreover, Hofmann et al., found that serum sE-cad levels might be a marker predicting response to preoperative chemotherapy for patients with locally advanced breast cancer [35]. Functional SNPs modulate the expression of both 
the membrane and the soluble E-cadherin forms in the same way. Since the two forms play opposite functions, the membrane form expressed in normal tissue acts as a tumor suppressor, while the soluble form associated with disease severity promotes tumor progression, this could explain why patients expected to have reduced E-cadherin expression have better survival whatever the severity of the disease.

\section{Conclusions}

This study provides novel information about the relationship between E-cadherin $(C D H 1)$ genetic variants and clinicopathological features and progression of $\mathrm{BC}$. The main finding of this study is the association of $C D H 1$ functional SNPs with overall survival in $\mathrm{BC}$, particularly in patients with a more aggressive tumor at onset or with recurrent metastatic BC. Our results support the fact that the CDH1 SNPs control disease severity and progression and could be a marker of disease outcome. These findings could be useful in selecting patients who should be monitored differently. Additional investigations on functional evaluation of $\mathrm{CDH} 1$ SNPs should be carried out to support our findings.

\begin{abstract}
Abbreviations
BC: breast cancer; PCR-RFLP: polymerase chain reaction-restriction fragment length polymorphism; wt: wild genotype; SNP: single nucleotide polymorphism; EMT: epithelial-mesenchymal transition; E-cadherin: epithelial-cadherin; $C D H 1$ : cadherin 1 gene; LD: linkage disequilibrium; ORs: odd ratios; Cls: 95\% confidence intervals; D': disequilibrium; DFS: disease-free survival; MFS: metastasis-free survival; OS: overall survival; sE-cad: soluble E-cadherin; MMPs: multiple matrix metalloproteinases.
\end{abstract}

\section{Authors' contributions}

$\mathrm{HE}, \mathrm{CL}$ and ZA designed the study. MH, KZ, MY, RY, GS, MW, BN and BN helped in sample collection. $M H$ assessed the molecular genotyping. $K Z, M Y, R Y, H E$, NB and NB generated the data. HE, MY, FK and B-H-AA analyzed the data. HE wrote the manuscript. All authors read and approved the final manuscript.

\begin{abstract}
Author details
${ }^{1}$ Laboratory of Molecular Immuno-Oncology, Faculty of Medicine of Monastir, Monastir University, 5019 Monastir, Tunisia. ${ }^{2}$ Faculty of Sciences of Bizerte, Carthage University, Bizerte, Tunisia. ${ }^{3}$ Higher Institute of Biotechnology of Monastir, Monastir University, Monastir, Tunisia. ${ }^{4}$ Cancer Research Chair, College of Medicine, King Saud University, Riyadh, Saudi Arabia. ${ }^{5}$ Department of Cancerology and Radiotherapy, Farhat Hached University Hospital, Sousse University, Sousse, Tunisia. ${ }^{6}$ Laboratory of Genetic Medicine and Immunology, Weill Cornell Medicine-Qatar, Education City, Qatar Foundation, Doha, Qatar. ${ }^{7}$ Department of Anatomy and Pathologic Cytology, Fattouma Bourguiba University Hospital, Monastir University, Monastir, Tunisia.
\end{abstract}

\section{Acknowledgements}

This work was supported by the Ministry of Higher Education and Scientific Research and by the Ministry of Health of the Republic of Tunisia. We thank Mr Adel Rdissi for English revision.

\section{Competing interests}

The authors declare that they have no competing interests.

\section{Availability of data and materials}

All the data presented is available upon request.

\section{Ethical approval}

All procedures performed in studies involving human participants were in accordance with the ethical standards of the National Ethical Committee.

\section{Funding}

The Ministry of Higher Education and Scientific Research have supported this work.

\section{Informed consent}

A written informed consent was obtained from all enrolled individuals prior to their participation.

Received: 29 August 2016 Accepted: 8 November 2016

Published online: 16 November 2016

\section{References}

1. Ferlay J, Soerjomataram I, Dikshit R, Eser S, Mathers C, Rebelo M, Parkin DM, Forman D, Bray F. Cancer incidence and mortality worldwide: sources, methods and major patterns in GLOBOCAN 2012. Int J Cancer. 2015:136:E359-86.

2. Giordano L, Bisanti L, Salamina G, Ancelle Park R, Sancho-Garnier H, Espinas J, Berling C, Rennert G, Castagno R, Dotti M, Jaramillo L, Segnan N, Euromed Cancer Working Group. The EUROMED CANCER network: state-of-art of cancer screening programmes in non-EU Mediterranean countries. Eur J Public Health. 2016;26:83-9.

3. Shan J, Mahfoudh W, Dsouza SP, Hassen E, Bouaouina N, Abdelhak S, Benhadjayed A, Memmi H, Mathew RA, Aigha II, Gabbouj S, Remadi Y, Chouchane L. Genome-Wide Association Studies (GWAS) breast cancer susceptibility loci in Arabs:susceptibility and prognostic implications in Tunisians. Breast Cancer Res Treat. 2012;135:715-24.

4. Mestiri S, Bouaouina N, Ahmed SB, Khedhaier A, Jrad BB, Remadi S, Chouchane L. Genetic variation in the tumor necrosis factor-alpha promoter region and in the stress protein hsp70-2: susceptibility and prognostic implications in breast carcinoma. Cancer. 2001;91:672-8.

5. Khedhaier A, Hassen E, Bouaouina N, Gabbouj S, Ahmed SB, Chouchane L. Implication of xenobiotic metabolizing enzyme gene (CYP2E1, CYP2C19, CYP2D6, mEH and NAT2) polymorphisms in breast carcinoma. BMC Cancer. 2008:8:109.

6. Snoussi K, Mahfoudh W, Bouaouina N, Fekih M, Khairi H, Helal AN, Chouchane L. Combined effects of IL-8 and CXCR2 gene polymorphisms on breast cancer susceptibility and aggressiveness. BMC Cancer. 2010;10:283.

7. Tsai JH, Yang J. Epithelial-mesenchymal plasticity in carcinoma metastasis. Genes Dev. 2013;27:2192-206.

8. Thiery JP. Epithelial-mesenchymal transitions in tumour progression. Nat Rev Cancer. 2002;2:442-54.

9. Van Roy F, Berx G. The cell-cell adhesion molecule E-cadherin. Cell Mol Life Sci. 2008;65:3756-88.

10. Shin Y, Kim IJ, Kang HC, Park JH, Park HR, Park HW, Park MA, Lee JS, Yoon KA, Ku JL, Park JG. The E-cadherin -347G-> GA promoter polymorphism and its effect on transcriptional regulation. Carcinogenesis. 2004:25:895-9.

11. Li LC, Chui RM, Sasaki M, Nakajima K, Perinchery G, Au HC, Nojima D, Carroll $\mathrm{P}$, Dahiya $\mathrm{R}$. A single nucleotide polymorphism in the E-cadherin gene promoteralters transcriptional activities. Cancer Res. 2000;60:873-6.

12. Jacobs G, Hellmig S, Huse K, Titz A, Franke A, Kwiatkowski R, Ott S, Kosmahl M, Fischbach W, Lucius R, Klapper W, Fölsch UR, Hampe J, Schreiber $\mathrm{S}$, Rosenstiel P. Polymorphisms in the $3^{\prime}$-untranslated region of the $\mathrm{CDH} 1$ gene are a risk factor for primary gastric diffuse large B-cell lymphoma. Haematologica. 2011;96:987-95.

13. Miller SA, Dykes DD, Polesky HF. A simple salting out procedure for extracting DNA from human nucleated cells. Nucleic Acids Res. 1988;16:1215.

14. Kiemeney LA, van Houwelingen KP, Bogaerts M, Witjes JA, Swinkels DW, denHeijer M, Franke B, Schalken JA, Verhaegh GW. Polymorphisms in the E-cadherin $(\mathrm{CDH} 1)$ gene promoter and the risk of bladder cancer. Eur J Cancer. 2006:42:3219-27.

15. Zhang XF, Wang YM, Ge H, Cao YY, Chen ZF, Wen DG, Guo W, Wang N, Li $\mathrm{Y}$, Zhang $\mathrm{H}$. Association of $\mathrm{CDH} 1$ single nucleotide polymorphisms with 
susceptibility toesophageal squamous cell carcinomas and gastric cardia carcinomas. Dis Esophagus. 2008;21:21-9.

16. Shi YY, He L. SHEsis, a powerful software platform for analyses of linkage disequilibrium, haplotype construction, and genetic association at polymorphism loci. Cell Res. 2005;15:97-8.

17. Stephens M, Smith NJ, Donnelly P. A new statistical method for haplotype reconstruction from population data. Am J Hum Genet. 2001;68:978-89.

18. Shabnaz S, Ahmed MU, Islam MS, Islam MR, Al-Mamun MM, Islam MS, Hasnat A. Breast cancer risk in relation to TP53 codon 72 and $\mathrm{CDH1}$ gene polymorphisms in the Bangladeshi women. Tumour Biol. 2016:37:7229-37.

19. Tipirisetti NR, Govatati S, Govatati S, Kandukuri LR, Cingeetham A, Singh L, Digumarti RR, Bhanoori M, Satti V. Association of E-cadherin single-nucleotide polymorphisms with the increased risk of breast cancer: a study in South Indian women. Genet Test Mol Biomarkers. 2013;17:494-500.

20. Chien MH, Yeh KT, Li YC, Hsieh YH, Lin CH, Weng MS, Kuo WH, Yang SF. Effects of E-cadherin ( $\mathrm{CDH} 1)$ gene promoter polymorphisms on the risk and clinicopathological development of hepatocellular carcinoma. J Surg Oncol. 2011;104:299-304.

21. Zhao L, Wang YX, Xi M, Liu SL, Zhang P, Luo LL, Liu MZ. Association between E-cadherin ( $\mathrm{CDH1}$ ) polymorphisms and pancreatic cancer risk in Han Chinese population. Int J Clin Exp Pathol. 2015;8:5753-60.

22. Kuraoka K, Oue N, Yokozaki H, Kitadai Y, Ito R, Nakayama H, Yasui W. Correlation of a single nucleotide polymorphism in the E-cadherin gene promoter with tumorigenesis and progression of gastric carcinoma in Japan. Int J Oncol. 2003;23:421-7.

23. Ardlie KG, Kruglyak L, Seielstad M. Patterns of linkage disequilibrium in the human genome. Nat Rev Genet. 2002;3:299-309.

24. Jia YM, Xie YT, Wang YJ, Han JY, Tian XX, Fang WG. Association of genetic polymorphisms in $\mathrm{CDH} 1$ and CTNNB1 with breast cancer susceptibility and patients' prognosis among Chinese han women. PLoS ONE. 2015;10:e0135865.

25. Goode EL, Dunning AM, Kuschel B, Healey CS, Day NE, Ponder BA, Easton DF, Pharoah PP. Effect of germ-line genetic variation on breast cancer survival in a population-based study. Cancer Res. 2002;62:3052-7.
26. Oka H, Shiozaki H, Kobayashi K, Inoue M, Tahara H, Kobayashi T, Takatsuka Y, Matsuyoshi N, Hirano S, Takeichi M, et al. Expression of E-cadherin cell adhesion molecules in human breast cancer tissues and its relationship to metastasis. Cancer Res. 1993;53:1696-701.

27. Siitonen SM, Kononen JT, Helin HJ, Rantala IS, Holli KA, Isola JJ. ReducedEcadherin expression is associated with invasiveness and unfavorable prognosis in breast cancer. Am J Clin Pathol. 1996;105:394-402.

28. Hunt NC, Douglas-Jones AG, Jasani B, Morgan JM, Pignatelli M. Loss of E-cadherin expression associated with lymph node metastases in small breast carcinomas. Virchows Arch. 1997;430:285-9.

29. Kowalski PJ, Rubin MA, Kleer CG. E-cadherin expression in primary carcinomas of the breast and its distant metastases. Breast Cancer Res. 2003;5:R217-22.

30. Rodriguez FJ, Lewis-Tuffin LJ, Anastasiadis PZ. E-cadherin's dark side: possible role in tumor progression. Biochim Biophys Acta. 2012;1826:23-31.

31. Nawrocki-Raby B, Gilles C, Polette M, Bruyneel E, Laronze JY, Bonnet N, Foidart JM, Mareel M, Birembaut P. Upregulation of MMPs by soluble E-cadherin in human lung tumor cells. Int J Cancer. 2003:105:790-5.

32. Brouxhon SM, Kyrkanides S, Teng X, Raja V, O'Banion MK, Clarke R, Byers S, Silberfeld A, Tornos C, Ma L. Monoclonal antibody against the ectodomain of E-cadherin (DECMA-1) suppresses breast carcinogenesis: involvement of theHER/PI3K/Akt/mTOR and IAP pathways. Clin Cancer Res. 2013;19:3234-46.

33. Brouxhon SM, Kyrkanides S, Teng X, Athar M, Ghazizadeh S, Simon M, O'Banion MK, Ma L. Soluble E-cadherin: a critical oncogene modulating receptor tyrosinekinases, MAPK and PI3K/Akt/mTOR signaling. Oncogene. 2014;33:225-35.

34. Liang Z, Sun $X Y, X u L C$, Fu RZ. Abnormal expression of serum soluble E-cadherin is correlated with clinicopathological features and prognosis of breast cancer. Med Sci Monit. 2014;20:2776-82.

35. Hofmann G, Balic M, Dandachi N, Resel M, Schippinger W, Regitnig P, Samonigg H, Bauernhofer T. The predictive value of serum soluble $\mathrm{E}$-cadherin levels in breast cancer patients undergoing preoperative systemic chemotherapy. Clin Biochem. 2013;46:1585-9.

\section{Submit your next manuscript to BioMed Central and we will help you at every step:}

- We accept pre-submission inquiries

- Our selector tool helps you to find the most relevant journal

- We provide round the clock customer support

- Convenient online submission

- Thorough peer review

- Inclusion in PubMed and all major indexing services

- Maximum visibility for your research

Submit your manuscript at www.biomedcentral.com/submit
O Biomed Central 